\title{
Native atretic coarctation of the aorta in a 37-year-old hypertensive woman, treated with a low-profile covered stent
}

\author{
M. W. Freund • A. M. Vollebregt • G. Krings • \\ E. P. A. Vonken • P. Agostoni $\cdot$ F. J. Meijboom
}

Published online: 21 May 2011

(C) The Author(s) 2011. This article is published with open access at Springerlink.com

We report on a 37-year-old woman with essential systemic hypertension. An MRI was performed because of weak femoral pulses, depicting a severe almost atretic coarctation of the aorta (Fig. 1). Angiography of the proximal distal thoracic aorta was simultaneously performed (Fig. 2a). The transverse arch was narrow $(16 \mathrm{~mm})$, as was the diameter of the terminal aortic arch distal to the left subclavian artery $(10 \mathrm{~mm})$. Distal of the coarctation the diameter of the descending aorta was $11 \mathrm{~mm}$. A trajectory of $2 \mathrm{~mm}$ in length seemed atretic. The

M. W. Freund $(\bowtie) \cdot$ G. Krings

Department of Pediatric Cardiology, University Medical Centre,

Lundlaan 6,

3584 EA Utrecht, the Netherlands

e-mail: m.w.freund@umcutrecht.nl

\section{A. M. Vollebregt}

Department of Pediatrics, University Medical Centre,

Lundlaan 6,

3584 EA Utrecht, the Netherlands

\section{E. P. A. Vonken}

Department of Radiology, University Medical Centre,

Heidelberglaan 100,

3584 CX Utrecht, the Netherlands

\section{P. Agostoni}

Department of Cardiology, University Medical Centre,

Heidelberglaan 100,

3584 CX Utrecht, the Netherlands

\section{F. J. Meijboom}

Department of Pediatric Cardiology and Cardiology,

University Medical Centre,

Lundlaan 6 ,

3584 EA Utrecht, the Netherlands atretic segment could be crossed in an antegrade fashion with a straight 0,014 in. coronary wire and balloon predilatation was performed with a $5 \mathrm{~mm}$ coronary balloon. Thereafter, a multi-purpose catheter could be advanced retrogradely across the coarctation segment. A 9 French

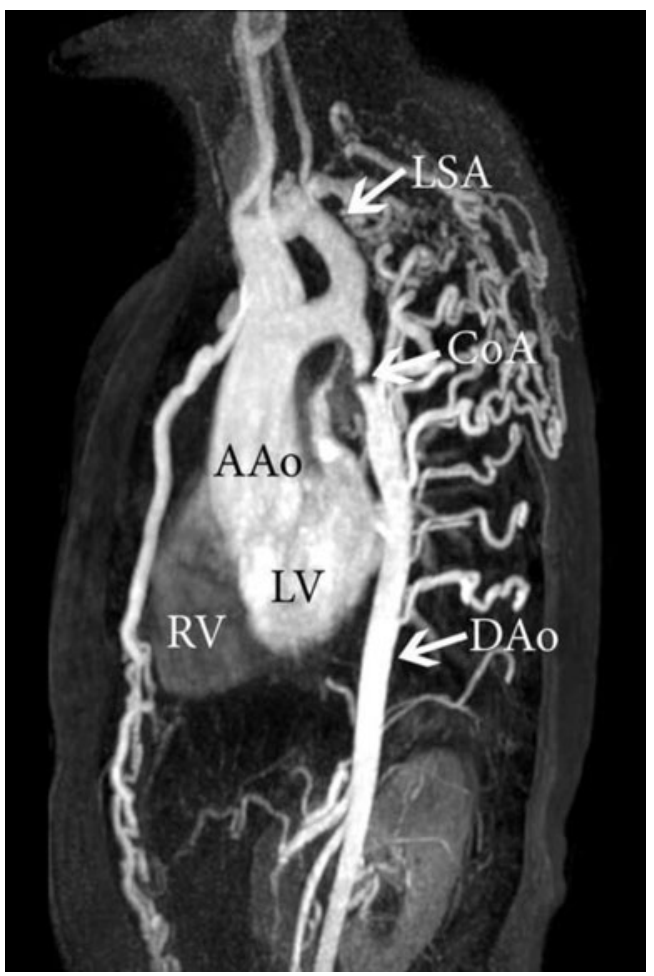

Fig. 1 MRI imaging of the left ventricle (LV), ascending aorta (AAo). The left subclavian artery (LSA) is dilated and the descending aorta (DAo) is hypoplastic. The coarctation imposes as atresia. There are numerous collaterals. RV: right ventricle 
Fig. 2 a Simultaneous angiography of the proximal and distal descending aorta; anterior projection. Atretic coarctation (CoA). Some small collaterals can be seen right of the coarctation. Abbreviations: Cath: catheter, DAo: descending aorta, LSA: left subclavian artery. L/R: left and right side of patient. $\mathbf{b}$ After stent-implantation (stent). Ao: transverse aorta. Left subclavian artery (LSA)
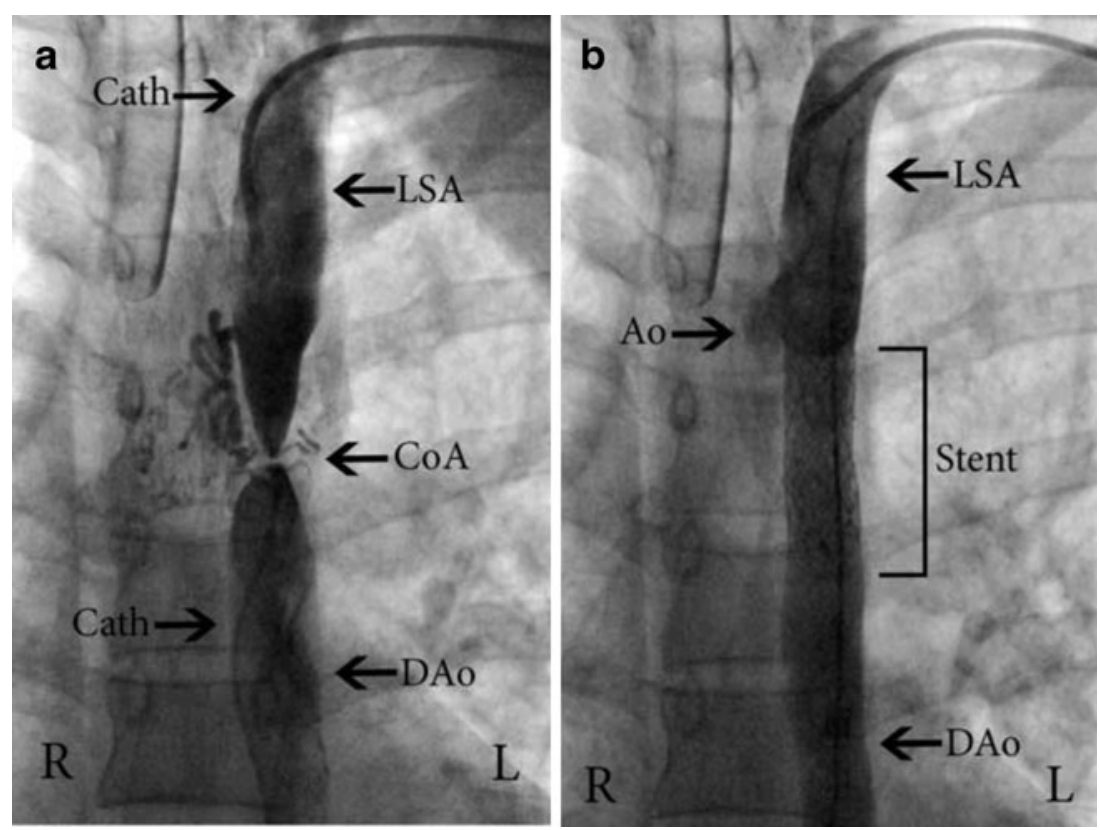

Mullins sheath (Cook) was advanced to the transverse aortic arch. A $41 \mathrm{~mm}$ long Advanta V12 premounted covered stent (Atrium, Hudson, USA) on a $12 \mathrm{~mm}$ high pressure balloon was implanted. Consecutive angiography revealed complete expansion of the stent up to $12 \mathrm{~mm}$ without residual stenosis, and no aneurysm formation (Fig. 2b).

In conclusion, treatment with placement of a lowprofile covered stent, using a simultaneous radial and femoral approach and pre-dilatation, delivered an excellent result without complications and a short hospital stay. The patient's blood pressure returned to normal and her antihypertensive medication could be stopped within 3 weeks after stent implantation. We emphasise that in so-called 'unexplained' systemic hypertension, especially in young adults, coarctation of the aorta has to be excluded [1,2]. When coarctation is confirmed primary stenting is the first choice therapeutic option [3-5].
Open Access This article is distributed under the terms of the Creative Commons Attribution Noncommercial License which permits any noncommercial use, distribution, and reproduction in any medium, provided the original author(s) and source are credited.

\section{References}

1. Ing FF, Starc TJ, Griffiths SP, Gersony WM. Early diagnosis of coarctation of the aorta in children: a continuing dilemma. Pediatrics. 1996;98:378-82.

2. Walhout RJ, Suttorp MJ, Mackaij GJ, Ernst JM, Plokker HW. Long-term outcome after balloon angioplasty of coarctation of the aorta in adolescents and adults: is aneurysm formation an issue? Catheter Cardiovasc Interv. 2001;73:549-56.

3. Harrison DA, McLaughlin PR, Lazzam C, Connelly M, Benson LN. Endovascular stents in the management of coarctation of the aorta in the adolescent and adult: one year follow up. Heart. 2001;85:561-6.

4. Bruckheimer E, Birk E, Santiago R, Dagan T, Esteves C, Pedra CA. Coarctation of the aorta treated with the Advanta V12 large diameter stent: acute results. Catheter Cardiovasc Interv. 2010;75:402-6.

5. Moltzer E, Roos-Hesselink JW, Yap SC, et al. Endovascular stenting for aortic (re)coarctation in adults. Neth Heart J. 2010;18:430-6. 